\title{
Investigation of the Relationship Between the Organizational Justice and the Organizational Performance and Productivity in the Health Center of Kermanshah Province
}

\author{
Yadollah Hamidi $^{1}(\mathbb{D})$, Shahla Shaterabadi ${ }^{2,3 *}$ (iD), Ali Reza Soltanian ${ }^{4}$
}

1. Department of Health Management and Economics, Research Center for Health Sciences, School of Public Health, Hamadan University of Medical Sciences, Hamadan, Iran

2. Department of Health Management and Economics, School of Public Health, Hamadan University of Medical Sciences, Hamadan, Iran

3. Population and Family Health Management, Children's Health Group, Health Center of Kermanshah Province, Kermanshah University of Medical Sciences, Kermanshah, Iran

4. Department of Biostatistics, Modeling of Non-communicable Diseases Research Center, School of Public Health, Hamadan University of Medical Sciences, Hamadan, Iran

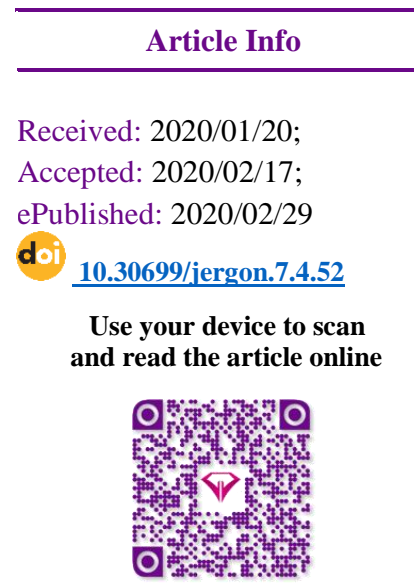

Corresponding Author Shahla Shaterabadi

Department of Health Management and Economics, School of Public Health, Hamadan University of Medical Sciences, Hamadan, Iran Population and Family Health Management, Children's Health Group, Health Center of Kermanshah Province, Kermanshah University of Medical Sciences, Kermanshah, Iran

Email:

Shaterabady@yahoo.com

Copyright $\odot$ 2020, This is an original open-access article distributed under the terms of the Creative Commons Attribution-noncommercial 4.0 International License which permits copy and redistribute of the material just in noncommercial usages with proper citation.

\section{How to Cite This Article:}

Hamidi Y, Shaterabadi S, Soltanian A R. Investigation of the Relationship Between the Organizational Justice and the Organizational Performance and Productivity in the Health Center of Kermanshah Province. Iran J Ergon. 2020; 7 (4):52-61.

\section{ABSTRACT}

Background and Objectives: One of the major challenges that managers face in competitive organizations is the improvement of the performance and productivity of the organization and understanding the factors affecting them. The promotion of the organizational performance requires managers to focus on the organizational justice and employees' motivation at work. The purpose of this study is to determine the relationship between organizational justice and organizational performance in the Health Center of Kermanshah Province.

Methods: The present work was a descriptive-analytic and correlation study. This study was performed on 166 employees of the Health Center of Kermanshah in summer 2019, selected by random sampling. Data were collected using two standard questionnaires: the organizational justice of Nihoff and Morman (1993), and the organizational performance of Hersey and Goldsmith (1980). Reliability of the questionnaires was assessed by the pilot study and Cronbach's alpha coefficient. Data analysis was performed using SPSS 16 software.

Results: The results showed that the average scores of the organizational justice and the organizational performance are $54.84 \pm 16.92$ and $140.54 \pm 18.66$, respectively. According to the results of Pearson correlation coefficient, there is significant relationship between the organizational justice and its dimensions with organizational performance $(P<0.001)$. However, the procedural justice has the more potential to predict the organizational performance.

Conclusion: The organizational justice is an important variable, strongly affecting the organizational performance. Therefore, managers need to pay particular attention to the justice as an important motivating factor for employees in order to improve the organizational performance and productivity.

Keywords: Organizational Justice, Organizational Performance, productivity 
بر رسى ارتباط عدالت سازمانى، عملكرد و بهرهورى سازمانى در حوزهُ معاونت بهداشتى استان كرمانشاه

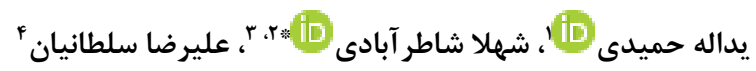

' ا. كروه مديريت و اقتصاد بهداشت، مركز تحقيقات علوم بهداشتى، دانشكدة بهداشت، دانشكاه علوميزشكى همدان، همدان، ايران

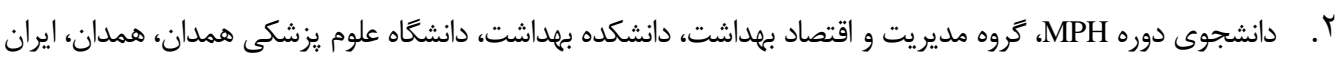

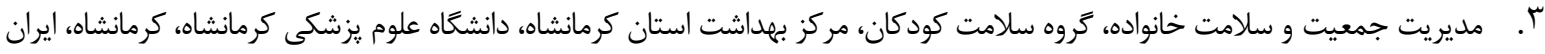

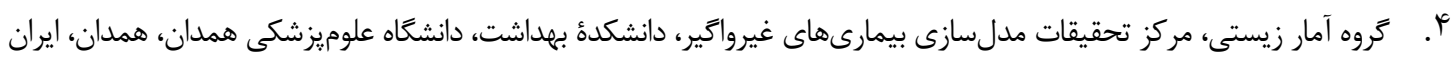

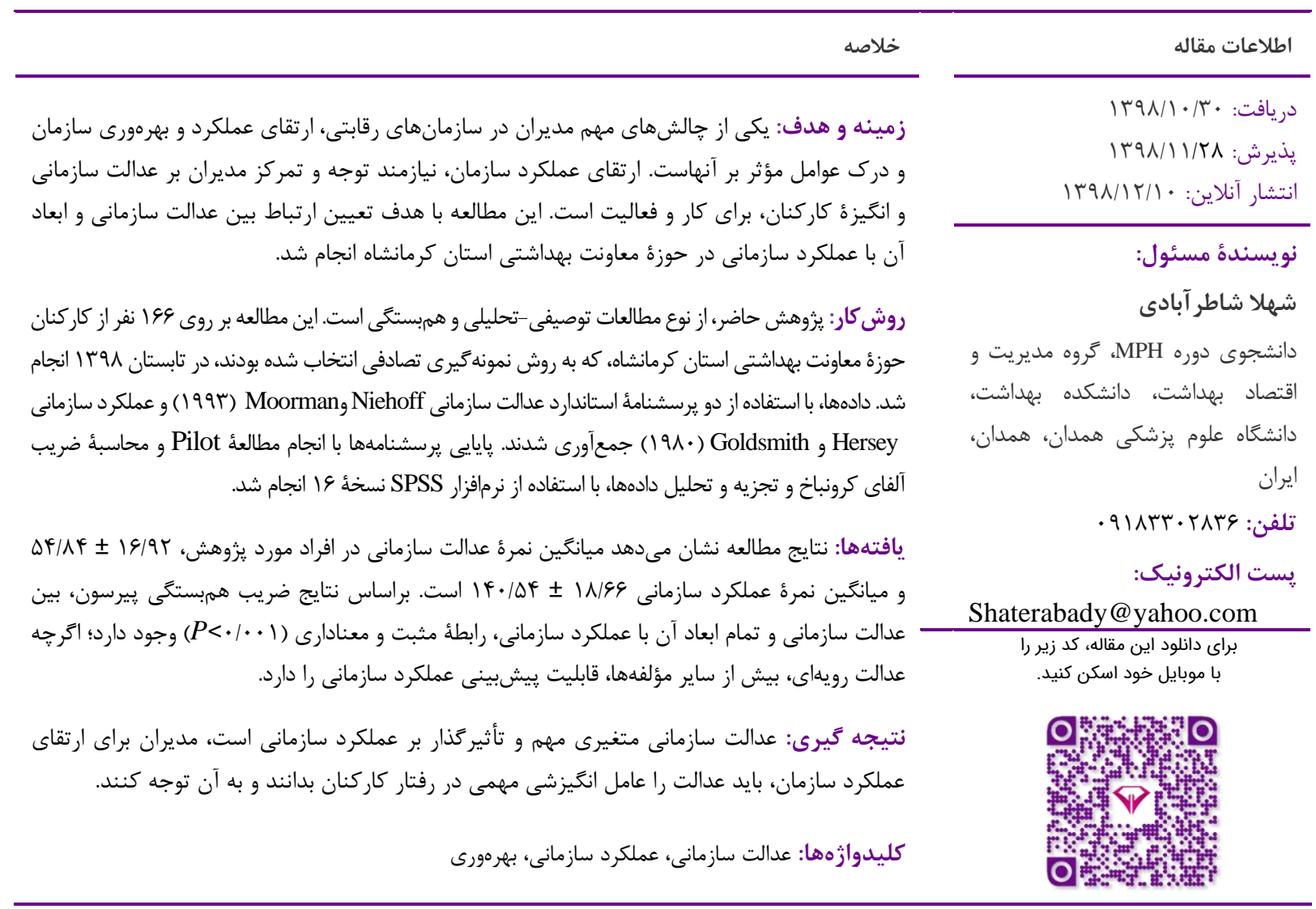

مقدمه

آكاهى از عوامل مؤثر بر عملكرد سازمانى و بهرهورى سازمان،

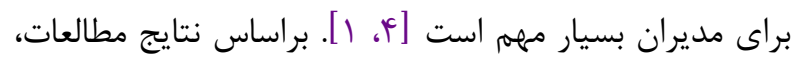

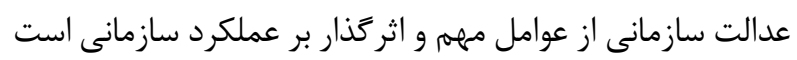

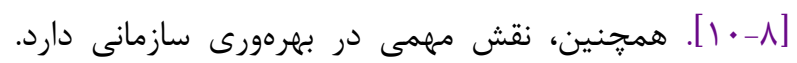

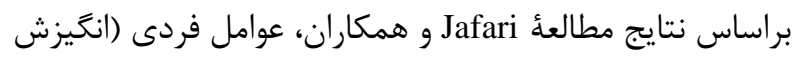

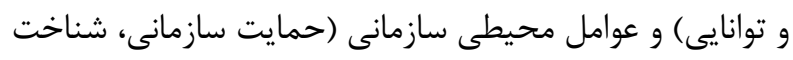

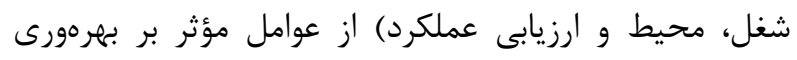

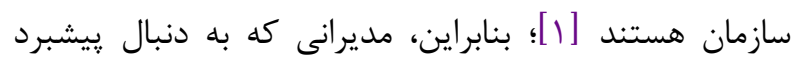

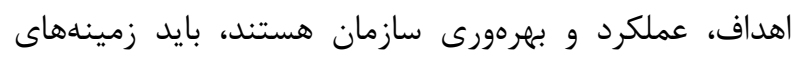

يكى از دغدغههاى مهم مديران در سازمانهاى يويا و

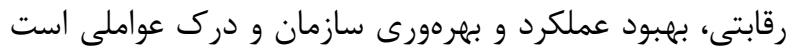

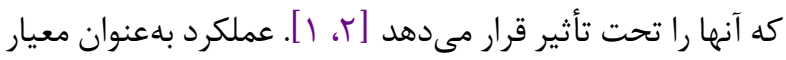

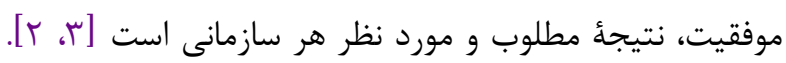

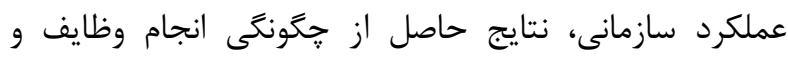

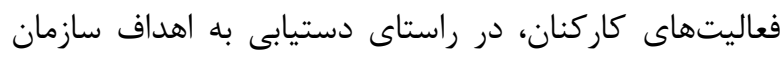

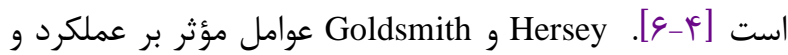
بهرهورى سازمانى را به هفت بعد اصلى توان، شناخت، حمايت،

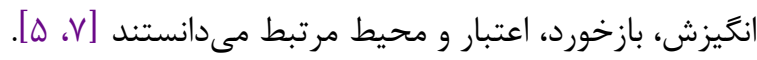


افراد و بلهنبال آن انتظارات مردم از نظام سلامت، مستلزم وجود

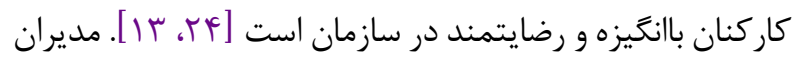
براى ايجاد انگيزش و جلب رضايت كاركنان، بايد به نيازهاى

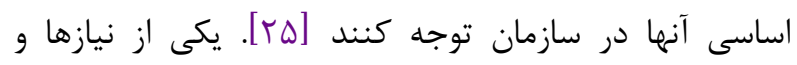

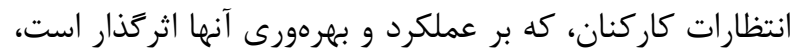

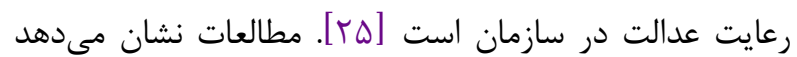

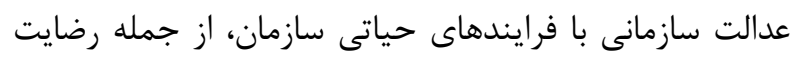

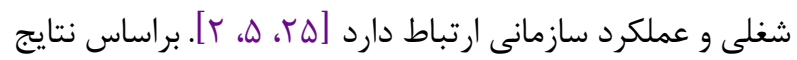

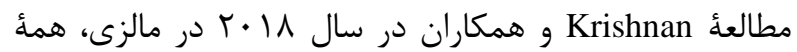

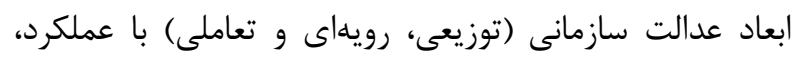

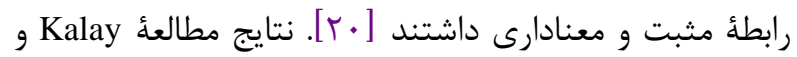

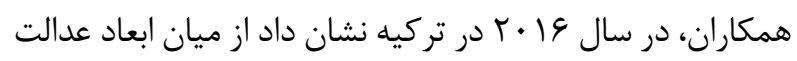

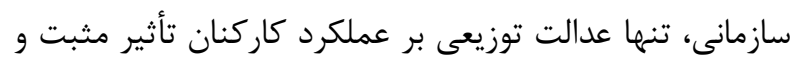

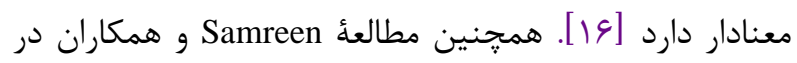

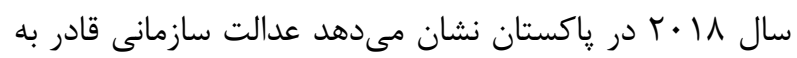
ييشبينى عملكرد سازمانى است؛ بهطورى كه افزايش يكى واحد

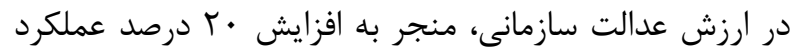

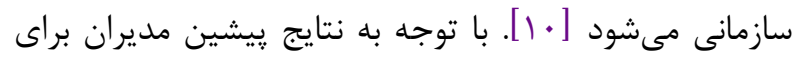

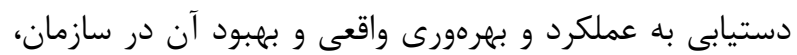

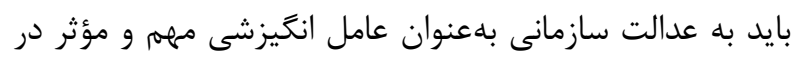

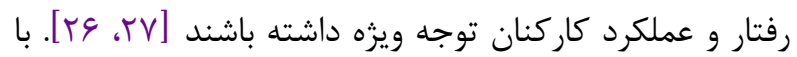
توجه به وظايف مههم و خطير كار كنان در حوزه معاونت بهداشتى بهمنظور حفظ و ارتقاى سلامت جامعه، طبيعى إست است

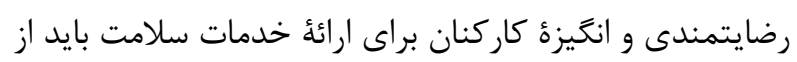

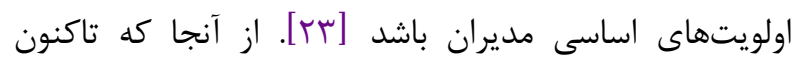
مطالعهاى در اين خصوص در معاونت بهداشتى استان كرمانشاه

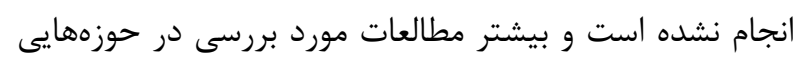

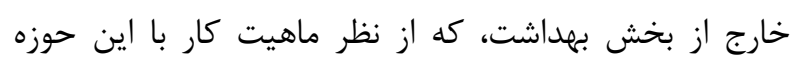

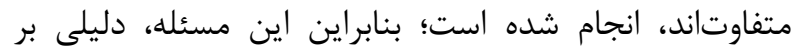

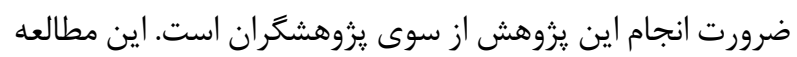

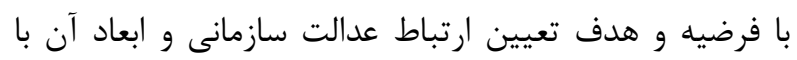
عملكرد سازمانى در حوزه معاونت بهداشتى استى استان كرمانشاه

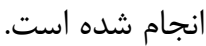

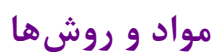

اين يزوهش، از نوع توصيفى -تحليلى و همبستتى است كه در حوزه معاونت بهداشتى استان كرمانشاه و در تابستان (تيرماه

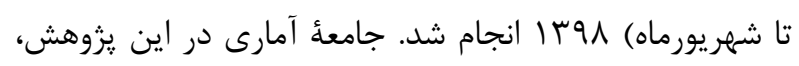

مناسبى از ايجاد عدالت، رضايت و انخيزه در كار كنان، براى انجام

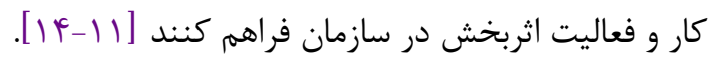
عدالت نياز اصلى و اساسى هر سازمان است كه كارن كاركنان

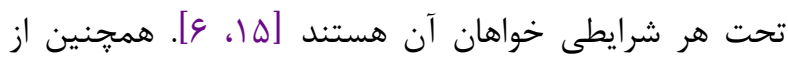

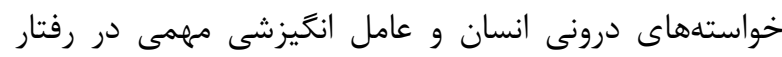

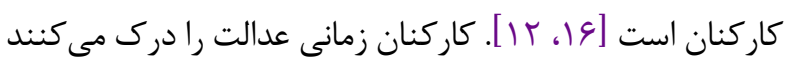

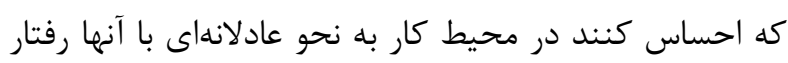

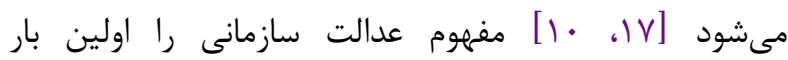

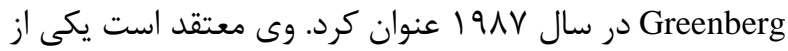

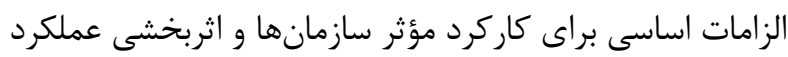

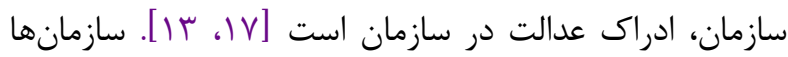
براى بيشرفت و بهبود عملكرد و بهرهورى، بايد درك درستى از ازئ

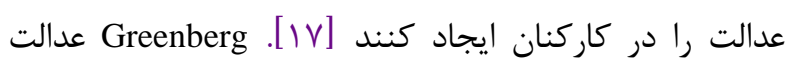

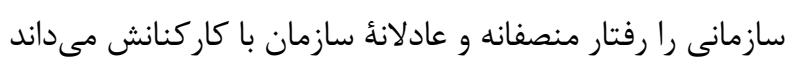
و معتقد است اين عامل، مقولهاى مههم در حفظ و بقاى سازمان

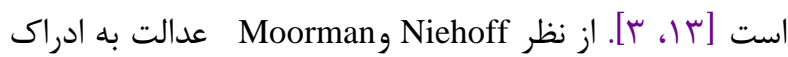

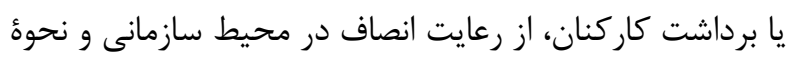

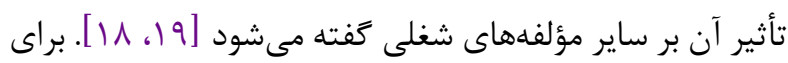
سنجش عدالت در سازمان سه بعد اصلى به شرح زير مطرح شده

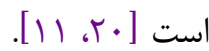
- عدالت توزيعى: به ادراك كاركنان از ميزان رعايت انصاف و عدالت در توزيع و تخصيص منابع و پاداشهاى ميان افراد آدران كفته مى شود. - عدالت رويهاى: به ادراك كاركنان از منصفانهبودن فرايند

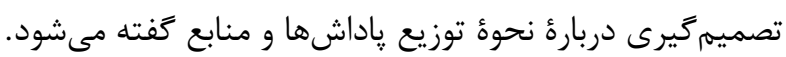

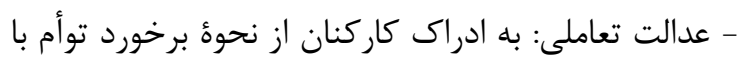

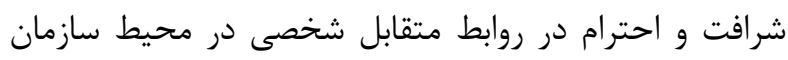
كَفته مىشود. افزايش عملكرد و بهرهورى سازمانى، ارتباط مستقيمى با

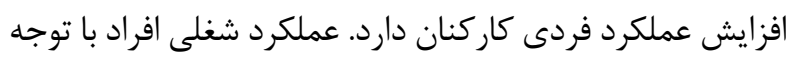

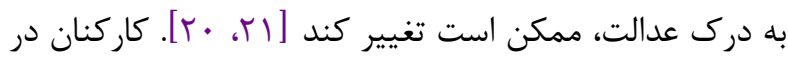

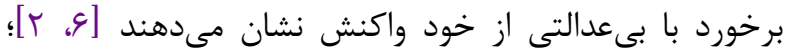

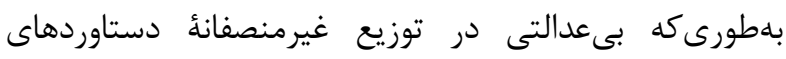

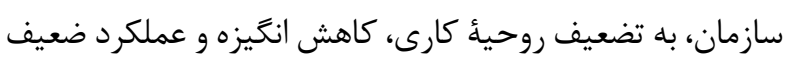

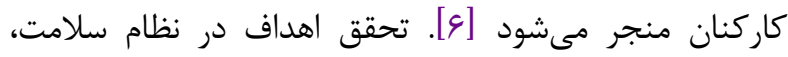

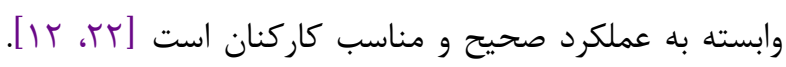

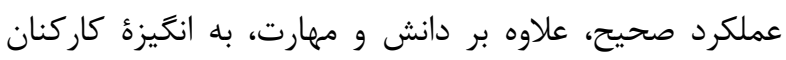

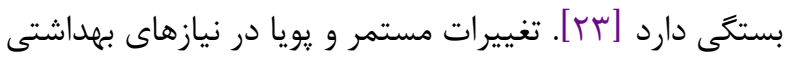


يرسيده شد. براى تجزيه و تحليل دادهها، از آمار توصيفى و استنباطى استفاده شد. براى توصيف متغيرهاى مورد مطالعه، از آمار توصيفى (شامل جداول فراوانى، ميانكين و انحراف معيار) و و

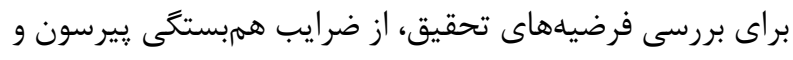
ركرسيون קندكانه با استفاده از نرمافزار SPSS نسخئ استفاده شد.

يافته ها

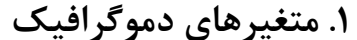

توزيع فراوانى متغيرهاى دموكر افيك در جدول آ آمده است.

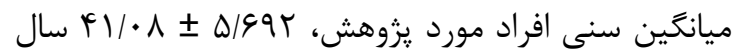

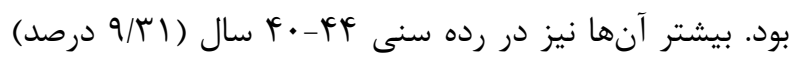

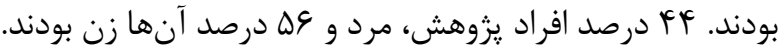

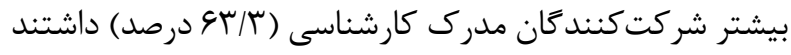

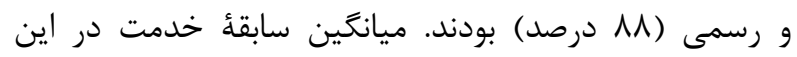

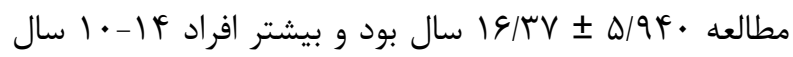

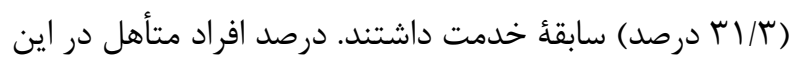

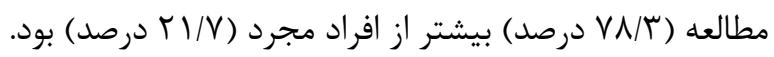
r. متغير مستقل عدالت سازمانى و ابعاد آن

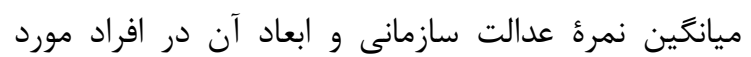
مطالعه، در جدول r نشان داده شده است.

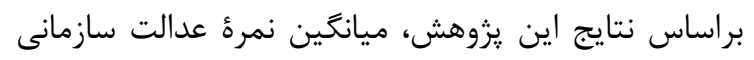

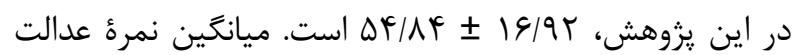

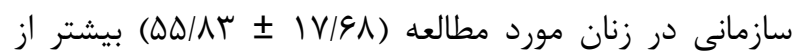

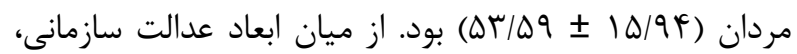

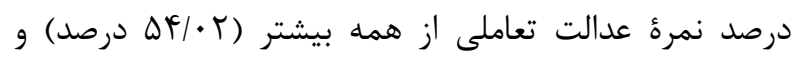

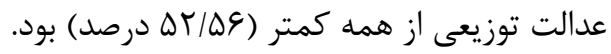
r. متغير وابستهُ عملكرد سازمانى و ابعاد آن آن

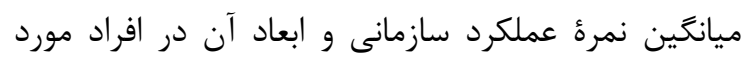
مطالعه، در جدول r نشان داده شده است.

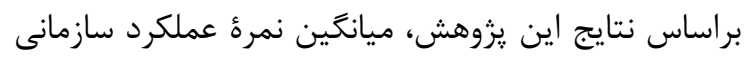
در جامعه مورد مطالعه، IN/99

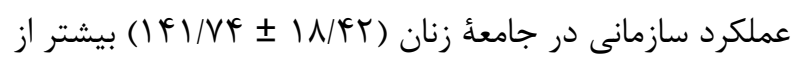

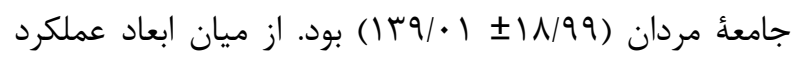

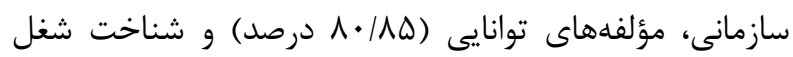

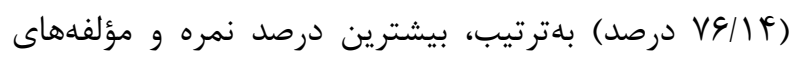
اعتبار ( بهترتيب بايينترين درصد نمره را داشتند.

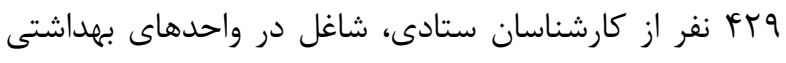

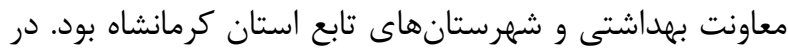

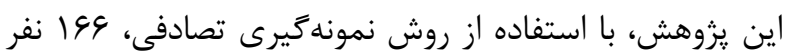

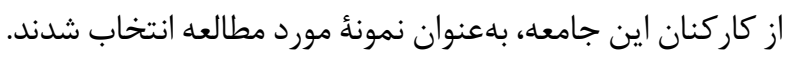
براى تعيين نمونهها در معاونت بهداشتى ( أ نفر ) و شهرستانها

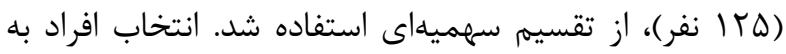

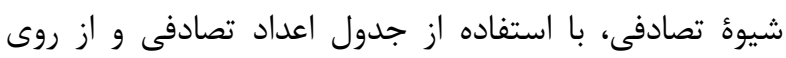
فهرست كارگزينى هر واحد انجام شد.

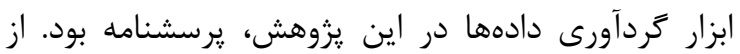
يرسشنامهاى استاندارد عدالت سازمانى إنى

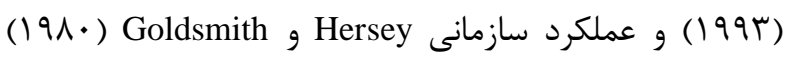

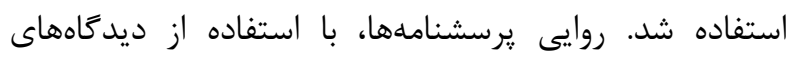

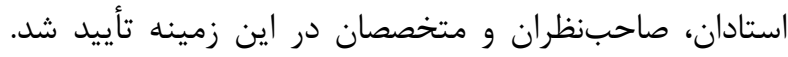

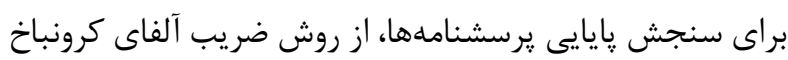

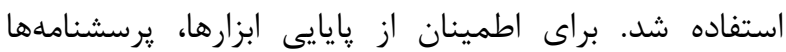

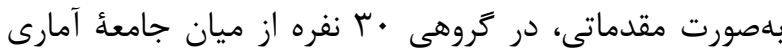

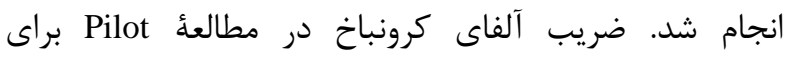

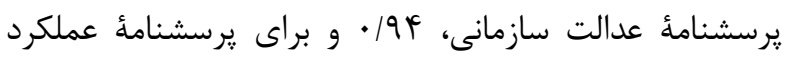

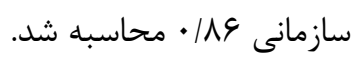

r. Moormang Niehoff يرسشنامة عدالت سازمانى يرسش دارد كه سه بعد عدالت سازمانى (عدالت توزيعى، رويهاى و تعاملى) را بررسى مى كند. اين يرسشنامه براساس مقياس ينج

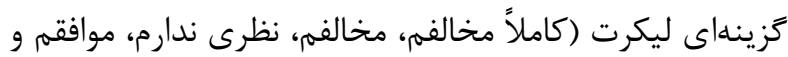

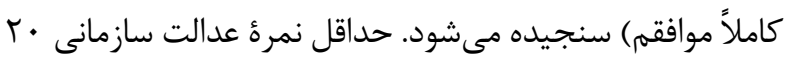

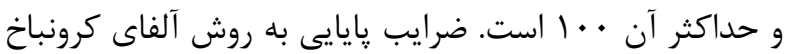

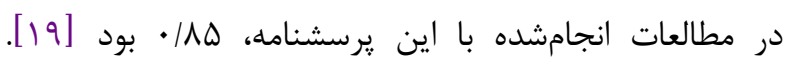

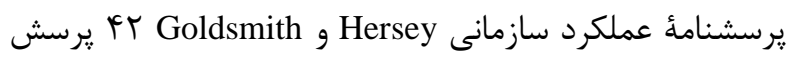

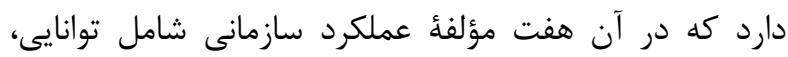
شناخت شغل، حمايت سازمانى، انخيزش، ارزيابى، اعتبار و محيط سنجش مىشود. اين يرسشنامه نيز براساس مقياس

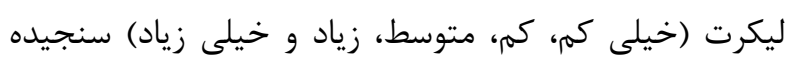
مىشود. حداقل نمرهٔ عملكرد سازمانى براى فرد بأ و و حداكثر •

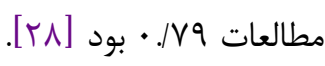
تأتر آنغير مستقل در اين يزوهش، عدالت سازمانى بود كه ميزان

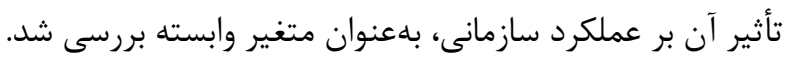

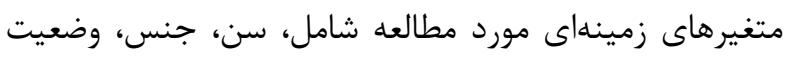

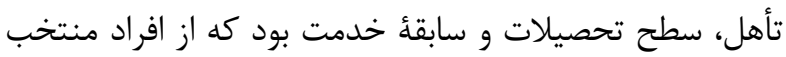




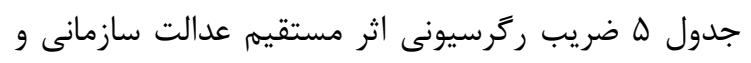

$$
\text { ابعاد آن را بر عملكرد سازمانى نشان مي دهريون. }
$$

بر اساس نتايج ضريب ركرسيونى در اين مطالعه، عدالت

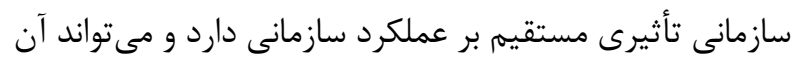

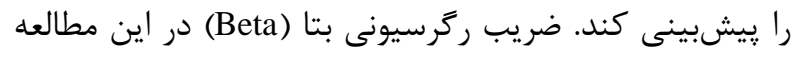

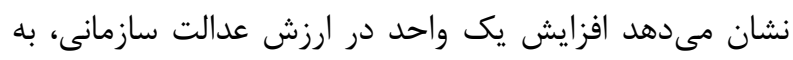

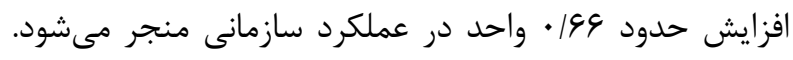

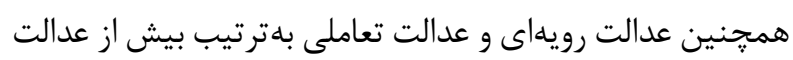

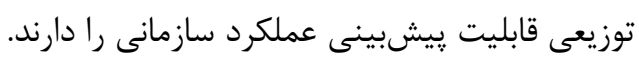

\section{F. رابطؤ بين متغير مستقل و وابسته}

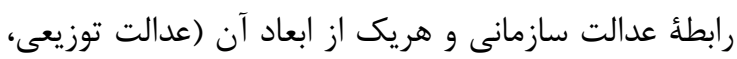

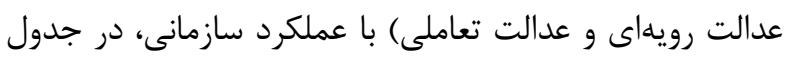

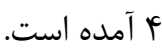

بر اساس نتايج ضريب همبستخى بيرسون در اين مطالعه،

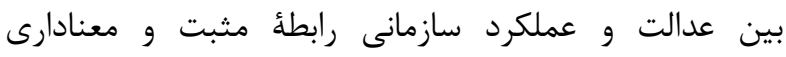

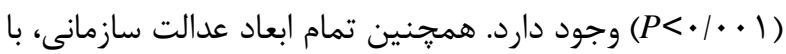

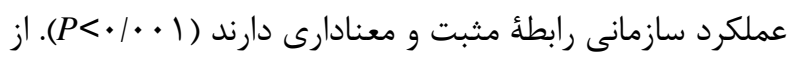

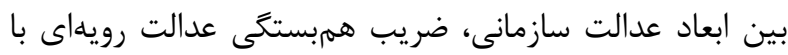
عملكرد سازمانى بيش از ساير مؤلفهها ارتباط دارد.

\section{ه. ضريب ركرسيونى بين متغير مستقل و وابسته}

جدول ا. توزيع فراوانى متغيرهاى دموكرافيك در افراد مورد يُروهش

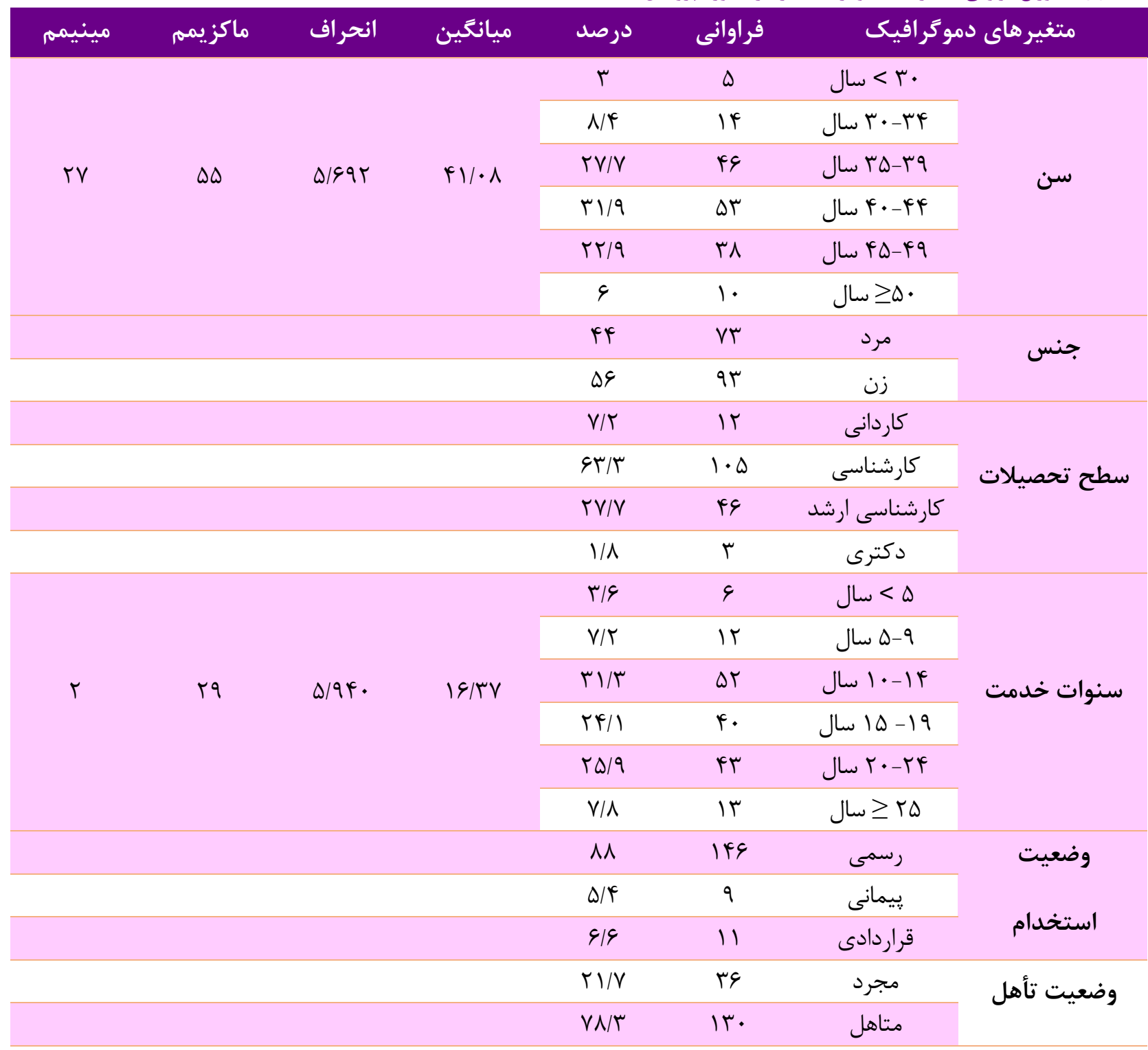


جدول r. ميانغين نمرة متغير مستقل (عدالت سازمانى) در افراد مورد يزوهش

\begin{tabular}{|c|c|c|c|c|}
\hline حداكثر نمره در & (درصد) نمره & انحراف معيار & ميانگين نمره & متغير ها \\
\hline$r \Delta$ & $\Delta T / \Delta \varphi$ & $F / T$ & $\| r / I F$ & عدالت توزيعى \\
\hline r. & $\Delta H / F \varphi$ & $\Delta / V \varphi$ & $|9| \cdot F$ & متغير مستقل \\
\hline$F \Delta$ & $\Delta F / \cdot r$ & $q / 4 V$ & $r \Delta / \& \varphi$ & عدالت تعاملى \\
\hline $1 \cdots$ & $\Delta F / \Lambda F$ & $19 / 9 r$ & $\Delta F / \Lambda F$ & عدالت سازمانى \\
\hline
\end{tabular}

جدول r. ميانغَين نمرة متغير وابسته (عملكرد سازمانى) در افراد مورد يثوهش

\begin{tabular}{|c|c|c|c|c|c|}
\hline حداكثر نمره در & (درصد) نمره & انحراف معيار & ميانگين نمره & متغيرها & \\
\hline$r$. & $\Lambda \cdot \mid \Lambda \Delta$ & $\Gamma / 10$ & $19 / 1 \mathrm{~V}$ & توانايى & \multirow{8}{*}{ متغير وابسته } \\
\hline ra & $V G / \mid f$ & $r / v q$ & rG/9D & شناخت شغل & \\
\hline$r \omega$ & $94 / 19$ & $r / \Lambda \cdot$ & $|9| \cdot r$ & حمايت سازمانى & \\
\hline r. & gr & r/VI & $1 \wedge / 9$. & انخيزش & \\
\hline$F \Delta$ & $9 \wedge / I V$ & D/T & $r \cdot 19 \Lambda$ & بازخورد عملكرد & \\
\hline r. & $\Delta \Lambda / \mathcal{F}$ & $F / \cdot 1$ & IV/DT & اعتبار & \\
\hline$r \Delta$ & $\Delta 9 / \uparrow \wedge$ & r/99 & IF/AV & ساز زارى محيطى & \\
\hline rle & $99 / 9 r$ & $11 / 99$ & $\mid F \cdot / D F$ & عملكرد سازمانى & \\
\hline
\end{tabular}

جدول f. رابطه عدالت سازمانى و هريك از ابعاد آن با عملكرد سازمانى

\begin{tabular}{|c|c|c|c|c|c|c|}
\hline سمازكر دانى & عازل & عدالت تعاملى & عدالت رويهاى & عدالت توزيعى & \multicolumn{2}{|c|}{ متغير ها } \\
\hline & & & & 1 & $r$ & \multirow{2}{*}{ عدالت توزيعى } \\
\hline & & & & - & $\mathrm{P}$ value & \\
\hline & & & 1 & $\cdot / \mathcal{F} \Delta V^{* * * *}$ & $\mathrm{r}$ & \multirow{2}{*}{ عدالت رويهاى } \\
\hline & & & - & $\cdot 1 \cdot$ & $\mathrm{P}$ value & \\
\hline & & 1 & $\cdot|\Lambda| Y^{* * *}$ & . MFY**** & $r$ & \multirow{2}{*}{ عدالت تعاملى } \\
\hline & & - & $\cdot / \cdots$ & $\cdot 1 \cdot \cdot$ & $\mathrm{P}$ value & \\
\hline & 1 & $.1948^{* * *}$ & $\cdot 19 \cdot 1^{* * *}$ & $\cdot|9 \Delta| * *$ & $r$ & \multirow{2}{*}{ عدازتمانى } \\
\hline & - & $\cdot 1 \cdots$ & $\cdot 1 \cdots$ & $\cdot 1 \cdots$ & P value & \\
\hline 1 & $\cdot \mid \Delta \psi f \varphi^{* * * *}$ & $\cdot / \mathbb{F V}$. $\%$ & $\cdot \mid \Delta Y V^{* * * *}$ & $\cdot / \Upsilon \wedge \mid$ **** & $r$ & \multirow{2}{*}{ سازمانى } \\
\hline- & $\cdot 1 \cdots$ & $\cdot 1 \cdot$ & $\cdot / \cdots$ & $\cdot 1 \cdot$ & $\mathrm{P}$ value & \\
\hline
\end{tabular}

${ }^{* *}$. Correlation is significant at the 0.01 level (2-tailed). 
جدول ه. ضريب ركرسيونى اثر مستقيم عدالت سازمانى بر عملكرد سازمانى در مدل مفهومى يزوهش

\begin{tabular}{|c|c|c|c|c|c|}
\hline \multicolumn{4}{|c|}{ ضر ايب غير استاندارد B } & \multirow{2}{*}{ ضرايب استانداردBeta } & \multirow{2}{*}{ متغير بيشبين ---> متغير ملاك } \\
\hline$P$ & C.R. & S.E. & Estimate & & \\
\hline$\cdot 1 \cdot$ & GIATA & $\cdot \mid \Delta g F$ & $r / \Lambda \Delta \mid$ & $\cdot / A V T$ & عدالت سازمانى ---> عدالت تعاملى \\
\hline \multirow[t]{2}{*}{$.1 \cdots$} & GIA\& & $\cdot$ /rGt & T/\&१९ &.$/ 9 Y \wedge$ & عدالت سازمانى--->> عدالت رويهاى \\
\hline & & & $1 / \cdots$ &.$|\Delta|$ & عدالت سازمانى--->> عدالت توزيعى \\
\hline$\cdot 1 \cdots$ & $\Delta / T T G$ & $\cdot 11 \cdot r$ & $\cdot \mid \Delta r \Lambda$ & $\cdot 19 \Delta 9$ & عدالت سازمانى ---> عملكرد سازمانى \\
\hline
\end{tabular}

به عدالت رويهاى و يايينترين نمره به عدالت تعاملى مربوط بود

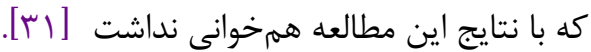
يافتههاى اين يزوهش، عملكرد خوبى را در جامعهُ مورد

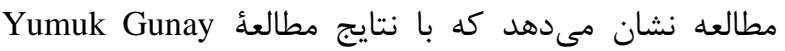

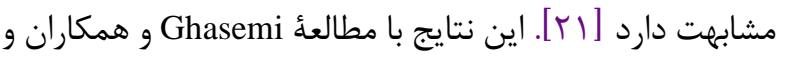
مطالعهُ Abasi و همكاران همخخوانى ندارد. از اين نظر كه آنها ميزان عملكرد شغلى را در حد متوسطى ارزيابى كرده بودند

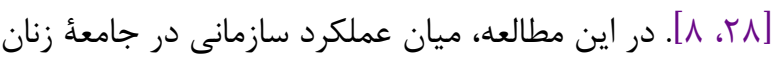
و مردان تفاوت معنادارى مشاهده نشد كه اين امر با نتايج

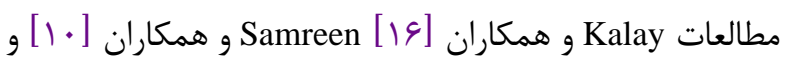
Barati مطالعه، ابعاد توانايى و شناخت شغل، بلهترتيب بيشترين درصد نمره را به خود اختصاص دادند؛ درحالى كه ابعاد اعتبار و و سازگارى محيطى بهترتيب، يايينترين درصد نمره را در اين

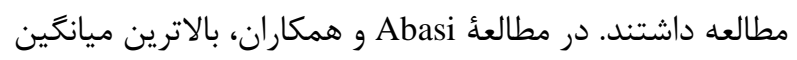
نمره، مربوط به بعد حمايت سازمانى بود كه با اين مطالعه

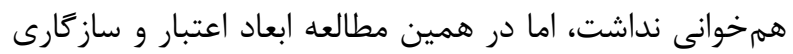

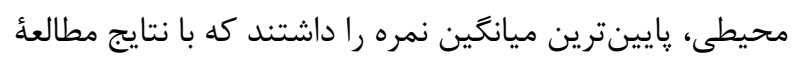

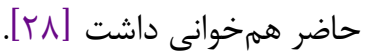
در اين مطالعه، عدالت سازمانى با عملكرد سازمانى، رابطهُ مثبت و معنادارى دارد. نتايج مطالعات Krishnan و همكاران

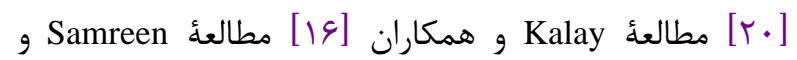

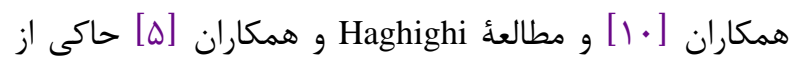
وجود رابطةٔ مثبت و معنادارى ميان عدالت و عملكرد سازمانى همان

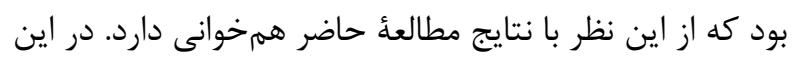

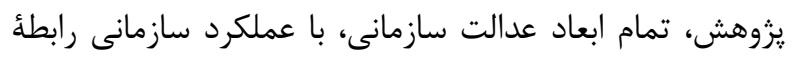

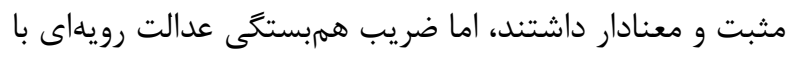

براساس نتايج اين يزوهش، ميزان عدالت در جامعهُ مورد مطالعه، در حد متوسط ارزيابى شد. اين نتايج، بيانگر ديدگاه حد واسط كاركنان، به درك عدالت در سازمان است. اين نتايج

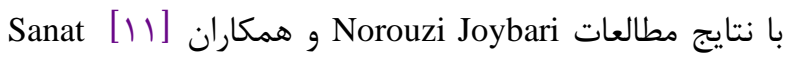

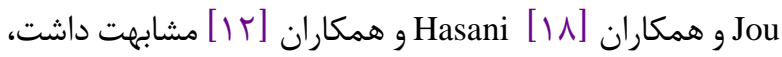
آنها نيز عدالت رادر جامعهُ مورد مطالعه متوسط ارزيابى كردند. در مطالعهُ حاضر، تفاوت معنى دارى ميان عدالت سازمانى در جامعd مردان و زنان مشاهده نشد كه اين امر با نتايج ديخر

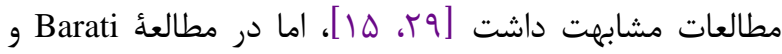
همكاران تفاوت ميانگين در جامعهُ زنان و مردان معنادار و اين مان مان ميانگين براى جامعهُ مردان بيشتر بود كه اين امر با نتايج اين دين

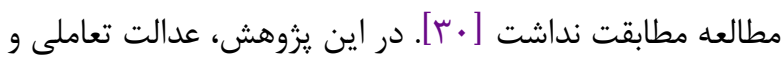
عدالت رويهاى، بلهترتيب درصد نمره بالاترى از عدالت توزيعى لئى

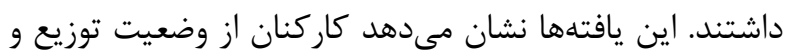
تخصيص امكانات و پاداشها (عدالت توزيعى) در محيط سازمان، نسبت به قوانين و فرايند تصميمزيرى در اين زمينه (عدالت رويهاى) يا نحوهُ برخورد عادلانه با آنان (عدالت تعاملى) رضايت كمترى دارند. اين نتايج با بسيارى از مطالعات برود از بان جمله Mohammadi Alborzi

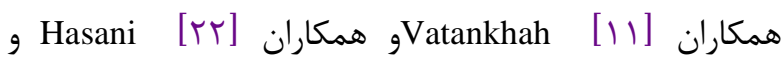

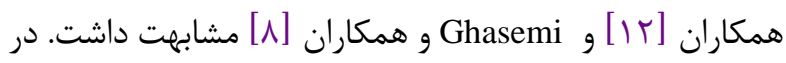
مطالعه Sanat Jou و همكاران و Delavare و همكاران بيشترين ميانكين نمره به عدالت تعاملى مربوط بود كه با نتايج اين مطالعه

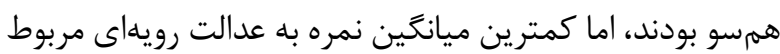

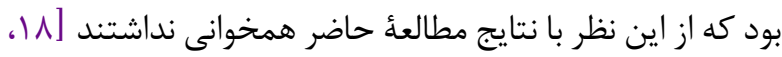

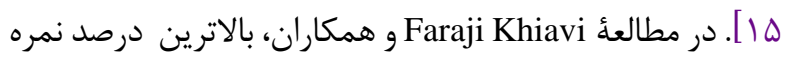




\section{نتيجه گَيرى}

با توجه به نتايج اين يزوهش، افزايش عدالت سازمانى به

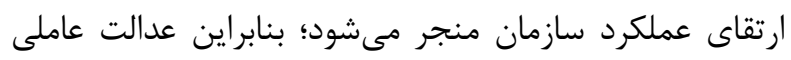

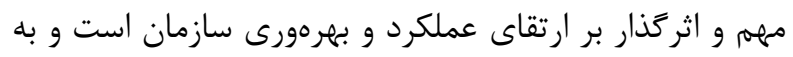

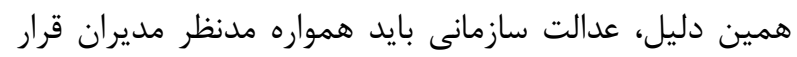

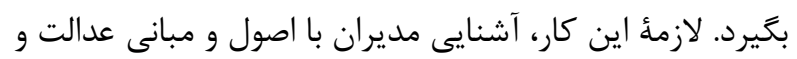

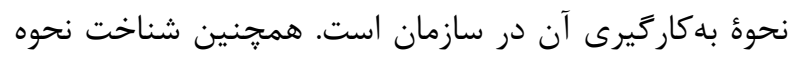

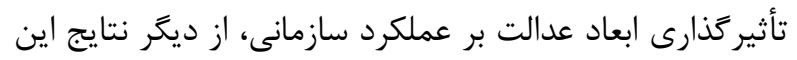

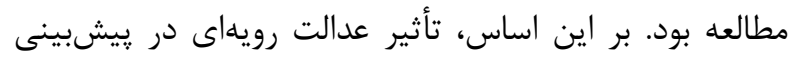
عملكرد سازمانى، بيش از ساير ابعاد آن بود؛ بنابر اين براى ارئ ارتقاى دئي

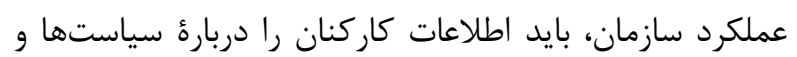

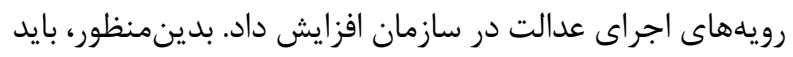

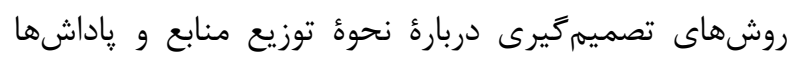
بهاطور واضح و شفاف، براى كار كنان توضيح داده شود تا كار كنان

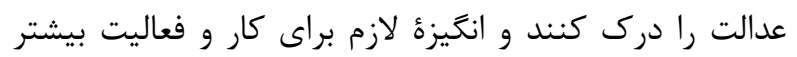

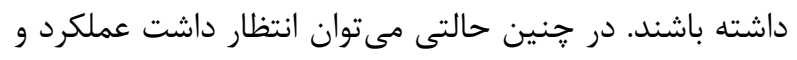

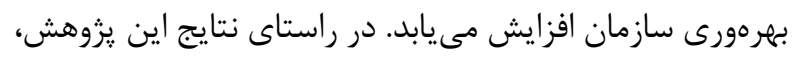

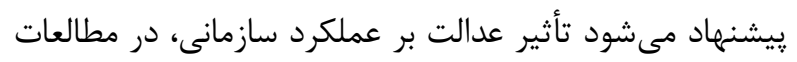

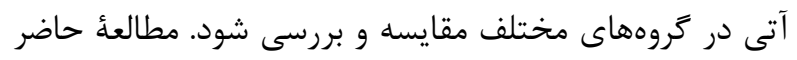

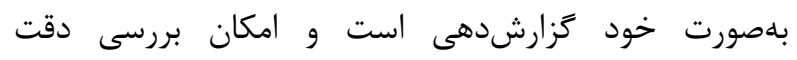

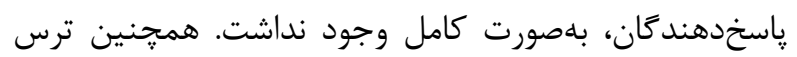

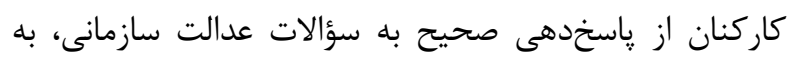

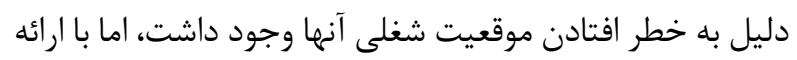

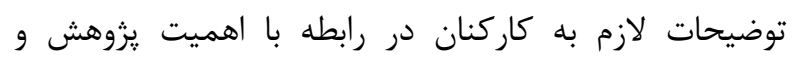
محرمانهبودن اطلاعات و انتشار نتايج بهصورت كلى، مشاركت و و الطان همكارى كاركنان جلب شد.

\section{تقدير و تشكر}

مطالعه حاضر بركرفته از پايان نامه اى با عنوان (مطالعه

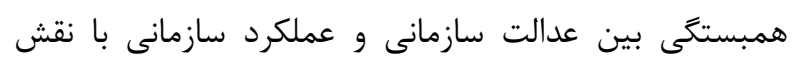

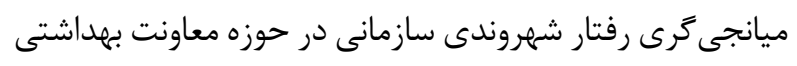

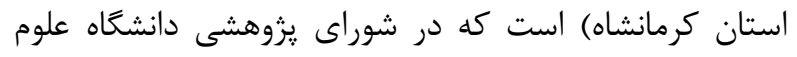

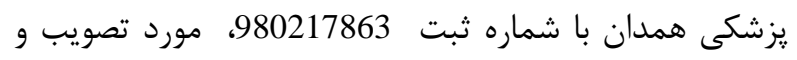
حمايت مالى قرار كرفت و بدينوسيله از شوراى يزوهشى دانشئ فئاه

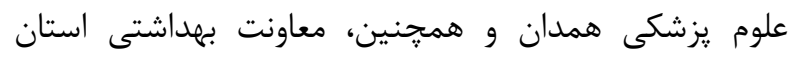

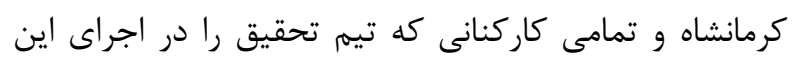
طرح يارى نمودند، تشكر و قدردانى مى تشود.
عملكرد سازمانى، بيشتر از ساير مؤلفهها بود. نتايج مطالعأ

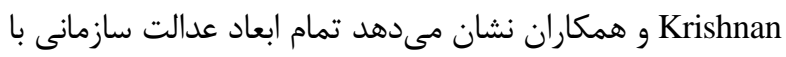

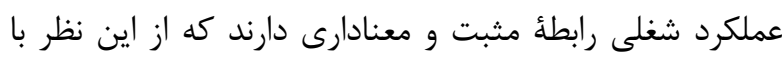

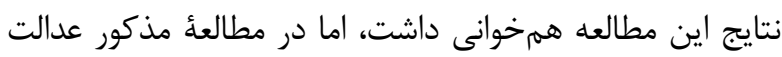

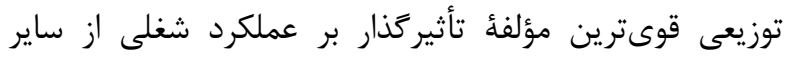

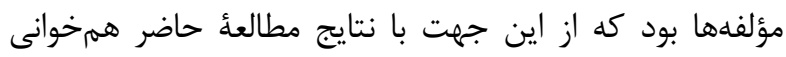

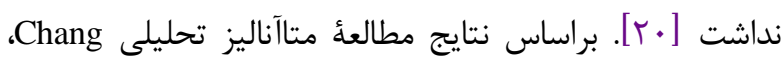

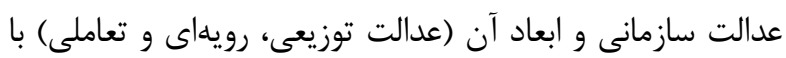

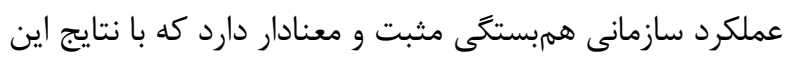

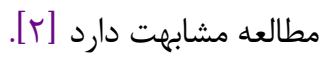

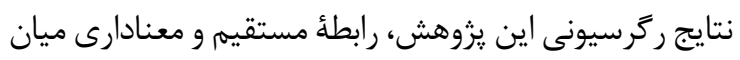

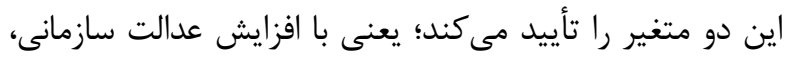

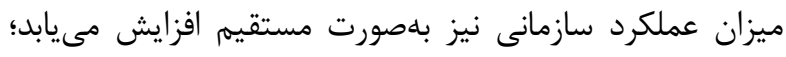

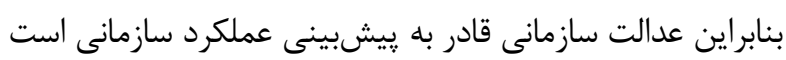

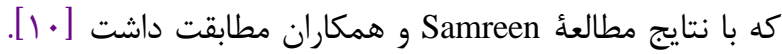

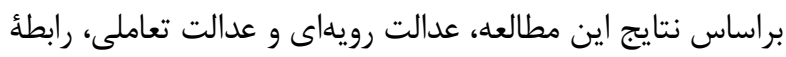

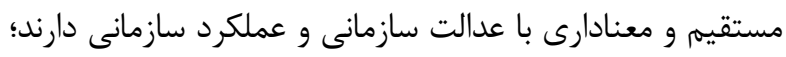

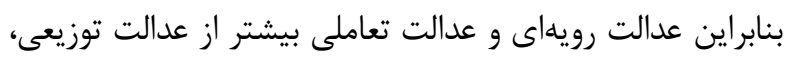

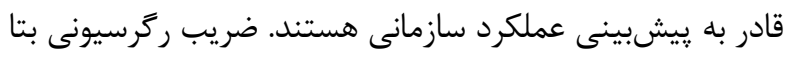
(Beta) توزيعى، بلهترتيب بيشترين و كمترين تأثير مستقيم را بر عملكرد

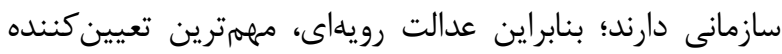

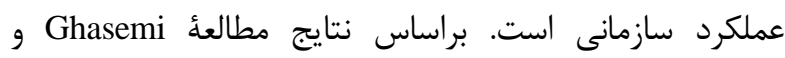

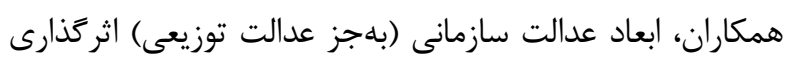

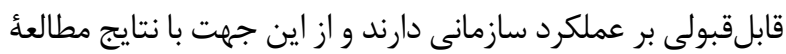

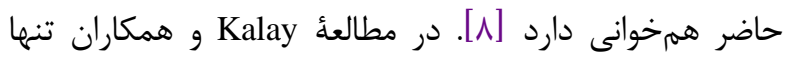

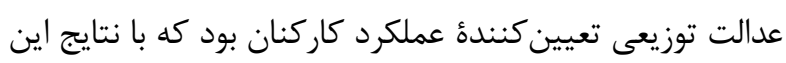
مطالعه همخوانى ندارد [919].

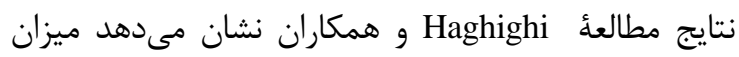

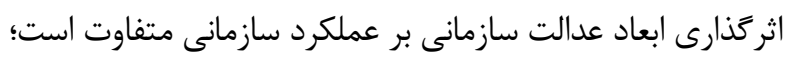

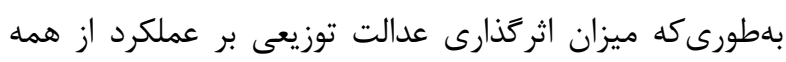

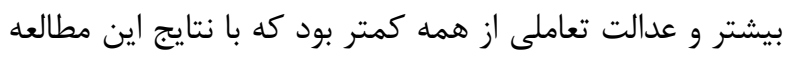

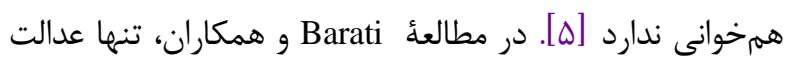

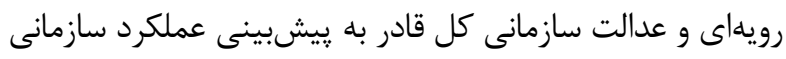

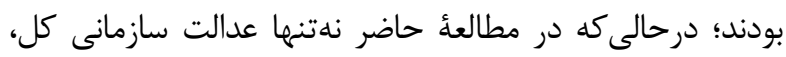

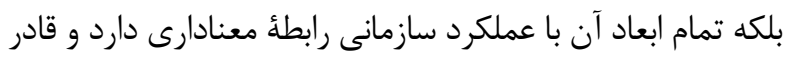

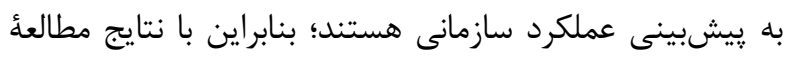
حاضر از اين نظر همخوانى نداشت [ـr]. 


$$
\text { منابع مالى }
$$

منابع مالى اين مطالعه توسط شوراى يزوهشى دانشعاه علوم

$$
\text { يزشكى همدان تأمين شده است. }
$$

\section{References}

1. Jafari A, Memarzade Tehran G. Identification of Effective Factors on Employee Productivity in A Military Health Organization. Journal of Military Medicine. 2017 Sep 10;19(3):234-44.

2. Chang CS. Relationships of organizational justice and organizational constraints with performance: a metaanalysis (Doctoral dissertation, Bowling Green State University).

3. Ramkissoon A. The moderating role of interactional justice on the relationship between justice and organizational citizenship behavior.

4. Sadeghi G, Ahmadi M, Yazdi MT. The relationship between organizational citizenship behavior and organizational performance (case study: Agricultural Jihad Organization of Mazandaran Province). Problems and Perspectives in Management. 2016;14(3):317-24. [DOI:10.21511/ppm.14(3-si).2016.03]

5. Haghighi MA, Ahmadi I, Ramin Mehr H. Investigating the Effect of Organizational Justice on Employees' Performance 2008(20):79-101 [Persian].

6. RouhollahI A, Vosoughi A, Torkzadeh AH. Investigating the role of citizenship behavior in relation to organizational justice And Job Stress with Organizational Performance Performance in Higher Education Centers Human Resource Studies Quarterly 2015;5(18):139-62 [Persian].

7. Jodaki M, Hassanpour HA. Prioritizing the Factors Affecting Employee Productivity Improvement Using Network Analysis Process (ANP) Technique (Case Study: National Standards Organization of Iran). Quarterly Journal of Standard and Quality Management. 2018;8(2):38-65 [Persian].

8. Ghasemi AR. The role of mediating organizational citizenship behavior on organizational justice and job performanceAhmad Reza Ghasemi. Management of organizational culture. 2013;12(1):63-82 [Persian].

9. Wang X, Liao J, Xia D, Chang T. The impact of organizational justice on work performance. International Journal of manpower. 2010 Sep 14;31(6):660-77. [DOI:10.1108/01437721011073364]

10. Ismail S, Iqbal Z, Adeel M. Impact of organizational justice and organizational citizenship behavior on employees performance. International Journal of Human Resource Studies.

2018;8(2):187-200. [DOI:10.5296/ijhrs.v8i2.13070]

\author{
تعارض منافع \\ بين نويسندكان هيجزَّنه تعارضى در منافع وجود ندارد.
}

11. Norouzi Joybari S, Bagherzade M, Baiky F, Taghavee A. Relationship between Organizational Justice and Organizational Citizenship Behavior among the Staff of Golestan University of Medical Sciences Journal of Management Development and Health Resources. 2017;1(1):47-54

12. Hasani M, kordlor G. The Relationship between Perceiving Organizational Justice with Desire to Quit, Job Satisfaction and Behavioral Organizational Behavior in Imam Reza Hospital, Urmia 2012;10(3):310-52 [Persian].

13. Fekghi Farahmand N. Prioritizing Organizational Justice for Improving Organizational Performance of Service Staff Journal of Behavioral Sciences. 2012(123):121-54 [Persian].

14. Hamidi Y, Bashirian S, Jalilian F, Eivazi M, Mirzaei Alavijeh M, Nasirzadeh M. Factors Affecting Job Satisfaction among the Staff of Teaching Hospitals in Hamadan, Iran. Health System Research. 2012:69-77.

15. Delavare A, Taghi Nasab MM. Organizational justice with organizational citizenship behavior in employees Allameh Tabataba'i University. 2015;1(4):1-20 [Persian].

16. Kalay F. The impact of organizational justice on employee performance: A survey in Turkey and Turkish context. International Journal of Human Resource Studies. 2016;6(1):1-20. [DOI:10.5296/ijhrs.v6i1.8854]

17. Norouzpour A. Investication Of The Relatioship Between Elements Of Orgazational Justic \& Organizational Citizenship Behaviors 2013: [Thesis In persian].

18. Sanat Jou A, Mahmodi h. Investigation the relationship between organizational justice and organizational citizenship behavior 2013:235-54 [Persian].

19. Niehoff BP, Moorman RH. Justice as a mediator of the relationship between methods of monitoring and organizational citizenship behavior. Academy of Management journal. 1993 Jun 1;36(3):527-56. [DOI:10.2307/256591]

20. Krishnan R, Loon KW, Yunus NA. Examining the Relationship between Organizational Justice and Job Performance. International Journal of Academic Research in Business and Social Sciences. 2018 Mar;8(3):466-77. [DOI:10.6007/IJARBSS/v8-i3/3942]

21. Yumuk Gunay G. Relationship between Job Satisfaction, Organizational Citizenship Behavior and Employee Performance: Sample of Edirne Financial Office Employees in Turkey. American International Journal of Contemporary Research. 2018;8:64-74. 
22. Vatankhah S, Yeganeh S, Nasiri T, Shams L, Atighehchian $\mathrm{G}$, Vaziri nasab H. The relationship between organizational justice and organizational citizenship behavior In hospitals of Tehran University of Medical Sciences Faculty of Paramedicine, Tehran University of Medical Sciences. 2013;7(6):544-55 [Persian].

23. Rafiei N, Khoshkam A, Heshmati H, Amini S. Job satisfaction and related factors among health center staff in Gonbad kavus city. Journal of Torbat Heydariyeh University of Medical Sciences. 2015 Apr 10;3(1):28-2.

24. Safavi M, Taghinezhad F, Aghaeinejad A, Taghinezhad Y, Shiekhi A. Predictors of organizational commitment among nurses. Quarterly Journal of Nursing Management. 2016 Mar 10;4(4):37-44.

25. Tavakoli AM, Rajabi M. The Relationship between Organizational Justice Perception and Job Satisfaction: a study on employees of Kerman University of Medical Sciences. Journal of health and development. 2013;2(1):2232.

26. Mohammadi Alborzi A, Niaze Azeri k, taghvaei Yazdi M. The Effect of Organizational Justice and Organizational Culture on Organizational Citizenship Behavior 2017;8(3):55-78.

27. Bahrami HR, Parsa ziabari L. The role of organizational climate moderator in relation between organizational citizenship behavior and organizational performance Journal of State Administration. 2014;3(7-8):51-61.

28. Abasi H, Fatahian n. The effect of strategic learning on organizational performance with mediating role of strategic agility (A case study: The departments of sport and youth in cities of Hamedan and Kermanshah). Research in Sport Management. 2018;8(15):43-60.

29. Jafari $\mathrm{P}$, Bidarian $\mathrm{S}$. The relationship between organizational justice and organizational citizenship behavior. Procedia-Social and Behavioral Sciences. 2012 Jan 1;47:1815-20. [DOI:10.1016/j.sbspro.2012.06.905]

30. Barati H, O'rizi H, Nouri A. Simple and Multiple Relationship of Organizational Justice with Job Performance in Isfahan Steel Company 2009(33):9-28.

31. Faraji Khiavi F, Bahrami F, Sharifi S, Mohammadi M. The Correlation between Organizational Justice and Organizational Citizenship Behavior in Educational Hospitals of Ahvaz Jundishapur University of Medical Sciences: A Short Report. Journal of Rafsanjan University of Medical Sciences. 2015 Nov 10;14(9):795-802. 